\title{
Active Management of the Third Stage of Labour: Knowledge and Challenges of Obstetric Caregivers in Selected Health Facilities in Fako Division, Cameroon
}

\author{
Tih William Ntchompbopughu ${ }^{1 *}$, Egbe Obinchemti Thomas ${ }^{1}$, Tendongfor Nicholas ${ }^{2}$ \\ ${ }^{1}$ Department of Obstetrics and Gynaecology, Faculty of Health Sciences, University of Buea, Buea, Cameroon \\ ${ }^{2}$ Department of Public Health and Hygiene, Faculty of Health Sciences, University of Buea, Buea, Cameroon \\ Email: ^williamtih3@gmail.com, toegbe@gmail.com, ntendongfor@gmail.com
}

How to cite this paper: Ntchompbopughu, T.W., Thomas, E.O. and Nicholas, T. (2021) Active Management of the Third Stage of Labour: Knowledge and Challenges of Obstetric Caregivers in Selected Health Facilities in Fako Division, Cameroon. Open Journal of Obstetrics and Gynecology, 11, 18151835.

https://doi.org/10.4236/ojog.2021.1112169

Received: October 11, 2021

Accepted: December 27, 2021

Published: December 30, 2021

Copyright $\odot 2021$ by author(s) and Scientific Research Publishing Inc. This work is licensed under the Creative Commons Attribution International License (CC BY 4.0).

http://creativecommons.org/licenses/by/4.0/

\begin{abstract}
Background: In Cameroon, the decrease in MMR (Maternal Mortality Ratio) from PPH (Postpartum Haemorrhage) despite the reported use of the Active Management of the Third Stage of Labour (AMTSL) is slower than what is required to achieve the Third Sustainable Development Goal (SDG3) hence the need to question obstetric caregivers' competence in AMTSL, as well as the factors hindering its proper use. We therefore aimed to assess obstetric caregivers' knowledge about AMTSL, as well as the determinants and barriers of AMTSL in selected hospitals in Fako Division, Cameroon. Methods: This was a hospital-based cross-sectional study of 150 participants recruited in 27 health facilities in Buea, Limbe and Tiko health districts from January 15, 2020, to March 31, 2020. Participants' socio-demographic and qualification characteristics, knowledge and challenges, and the references guiding their practice of AMTSL were collected using a structured questionnaire. AMTSL knowledge was categorized as poor or good and the determinants of good AMTSL knowledge were evaluated. The data was analyzed in SPSS version 25.0. Results: Of the 150 caregivers interviewed, only $48.7 \%$ had good knowledge of AMTSL. In logistic models, participants' use of AMTSL increased Good knowledge of AMTSL (AOR: 12.96, CI: $1.12-150.3, p=0.04$ ). Unavailability of drugs and/or equipment, insufficient staff coverage and lack of knowledge and training of the staff were the major challenges reported. Conclusion: Obstetric caregivers in Fako division have knowledge gaps and face numerous challenges in AMTSL use, which could account for the consistently high MMR from PPH. Filling this knowledge gap and mitigating the challenges of these caregivers would certainly accelerate progress towards the achievement of SDG3.
\end{abstract}




\section{Keywords}

Active Management of the Third Stage of Labour, Postpartum Haemorrhage, Obstetric Caregivers, Knowledge, Challenges, Determinants

\section{Background}

Despite the great role played by the Active Management of the Third Stage of Labour (AMTSL) over the years to reduce the burden of Postpartum Haemorrhage (PPH) and Maternal Mortality Ratio (MMR) [1], the MMRs in many low and middle-income countries are still quite high, for example, in Nigeria (814 per 100,000 live births), Tanzania (398 per 100,000 live births), Ethiopia (353 per 100,000 live births), Ghana (319 per 100,000 live births) in 2015 [2] and Cameroon (467 per 100,000 live births) in 2018 [3]. This high MMR in Cameroon concurs with the consistently high burden of $\mathrm{PPH}$ despite the utilization of AMTSL as demonstrated by studies conducted at the Douala General Hospital and the University Teaching Hospital Yaoundé in 2008 and 2013 which reported prevalences of primary $\mathrm{PPH}$ of $1.68 \%$ and $4.1 \%$ respectively [4]. A prevalence of primary $\mathrm{PPH}$ of $13.9 \%$ was reported at the University Teaching Hospital Yaoundé in 2014 [5] and 23.6\% at the Bonassama District Hospital in 2015 [4] [6], which were quite high. Nevertheless, Cameroon has shown great improvement in their MMRs over the years as reported in the Demographic and Health Surveys (DHS); from 784 per 100,000 live births in 2014 [7] to 467 per 100,000 live births in 2018 [8]. However, in spite of this great improvement, these consistently high MMR and prevalences of PPH display slow progress towards achieving the Third Sustainable Development Goal (SDG3).

However, it has been shown that the practice of AMTSL by obstetric caregivers in Cameroon and other low and middle-income countries is not consistent with the recommendations of the International Federation of Obstetrics and Gynaecology (FIGO), especially keeping in mind that a satisfactory level of knowledge and skills, a critical judgment and access to good equipment are mandatory for every birth attendant to perform AMTSL [1]. Moreover, studies conducted in Ethiopia, Nigeria and Ghana highlighted inadequate knowledge, lack of training, communication difficulties between more- and less-experienced caregivers, inadequate staff coverage and other socio-demographic factors as some of the causes of these lapses [8] [9] [10]. This, together with the high MMR and prevalence of PPH in Cameroon despite the reported use of AMTSL, therefore, raised the argument that AMTSL may not be properly done by the obstetric caregivers. We thus hypothesized that the knowledge and practice of AMTSL by caregivers are low while the challenges are numerous in selected hospitals in Fako Division, Cameroon. This highlighted the necessity to study the AMTSL knowledge and practice of obstetric caregivers and their challenges to AMTSL use in selected hospitals in Fako Division, Cameroon. 
This study aimed to assess obstetric caregivers' knowledge about AMTSL, as well as the determinants of and challenges to AMTSL use in selected hospitals in Fako Division, Cameroon.

\section{Materials and Methods}

This was a hospital-based cross-sectional study carried out from January 15, 2020, to March 31, 2020. Obstetric caregivers in selected health facilities in Buea, Tiko and Limbe health districts were enrolled in the study. A Two-stage cluster sampling method was used to select the health districts and health facilities under study. Simple random sampling by balloting was used to select the health districts among Buea, Limbe, Tiko and Muyuka health districts of the Fako division. Tiko, Buea and Limbe health districts were selected. A sampling frame of the health facilities under these health districts was drawn using information from the District Health Offices of the three respective health districts under the study.

Non-probability sampling (Purposive sampling) was done to select the health facilities (in both the private and public sectors) included in the study. The criteria for selection of health facilities were as follows; health facilities with a maternity unit, health facilities with registered information at the District Health Offices and health facilities with obstetric caregivers in greater numbers. A census approach, where all the obstetric caregivers approached in the health facilities under study were assessed and used to effectively meet our sample size (Table 1).

The Lorentz formula for estimation of minimum sample size for the study was used with a Confidence interval set at $95 \%$ and a five percent level of precision (standard error);

$$
n=z^{2} p(1-p) / d^{2}
$$

where $n=$ minimum sample size;

$Z=$ standard normal variant $=1.96$ at a $95 \%$ confidence interval;

$p=$ estimated proportion of the competent obstetric caregivers [11];

$d=$ level of precision $=5 \%$ or 0.05 .

A similar study was carried out in the Dar Es Salaam Municipal Hospitals of Tanzania in 2011 and the proportion of competent midwives on AMTSL was recorded as $10 \%$ [11]. Thus our $\mathrm{p}$ for this study was $10 \%$.

Thus; the sample size $n=(1.96)^{2} \times(0.1)(1-0.1) /(0.05)^{2}=138.2976$.

Therefore our minimum sample size of 139 obstetric caregivers was required for the study.

Those who gave written consent completed a self-administered semi-structured questionnaire to collect data on their knowledge of AMTSL, the challenges they faced concerning its use, the recommendations they had for better AMTSL practice and the references guiding their practice of AMTSL. The questionnaire was adapted from similar studies carried out in Nigeria $(2015,2018)$ and Ethiopia 
Table 1. Health facilities and recruited participants under the study.

\begin{tabular}{|c|c|c|c|c|}
\hline SN & Health facility & $\begin{array}{c}\text { Level of } \\
\text { hospital } \\
\text { care }\end{array}$ & $\begin{array}{l}\text { Health } \\
\text { district }\end{array}$ & $\begin{array}{l}\text { Number of } \\
\text { caregivers } \\
\text { recruited }\end{array}$ \\
\hline 1. & Limbe Regional Hospital (LRH) & Secondary & Limbe & 7 \\
\hline 2. & Limbe District Hospital (BOTA) & Primary & Limbe & 10 \\
\hline 3. & CMA Limbe & Primary & Limbe & 11 \\
\hline 4. & CMA Batoke & Primary & Limbe & 4 \\
\hline 5. & CMA Bojongo & Primary & Limbe & 8 \\
\hline 6. & Larosbi Maternity & Primary & Limbe & 2 \\
\hline 7. & Family Health Care Foundation & Primary & Limbe & 6 \\
\hline 8. & Buea Regional Hospital (BRH) & Primary & Buea & 15 \\
\hline 9. & CMA Muea & Primary & Buea & 5 \\
\hline 10. & CMA Mile 16 & Primary & Buea & 7 \\
\hline 11. & CMA Buea Town & Primary & Buea & 4 \\
\hline 12. & CMA Buea Road & Primary & Buea & 10 \\
\hline 13. & Mount Mary Hospital & Primary & Buea & 10 \\
\hline 14. & Solidarity Health Foundation & Primary & Buea & 11 \\
\hline 15. & $7^{\text {th }}$ Day Adventist Health Center & Primary & Buea & 11 \\
\hline 16. & Dr Kahwa Health Center & Primary & Buea & 8 \\
\hline 17. & $\begin{array}{l}\text { Molyko Integrated Health Center } \\
\text { (IHC) }\end{array}$ & Primary & Buea & 3 \\
\hline 18. & Tiko District Hospital (TDH) & Primary & Tiko & 9 \\
\hline 19. & CDC Cottage Hospital Tiko & Primary & Tiko & 10 \\
\hline 20. & $\begin{array}{l}\text { Regina Pacis Catholic Missionary } \\
\text { Hospital Mutengene }\end{array}$ & Primary & Tiko & 9 \\
\hline 21. & CMA Mutengene & Primary & Tiko & 10 \\
\hline 22. & CMA Tiko Holforth & Primary & Tiko & 9 \\
\hline 23. & Atlantic Medical Foundation & Primary & Tiko & 5 \\
\hline 24. & St. Luke Medical Center & Primary & Buea & $\mathrm{N} / \mathrm{A}$ \\
\hline 25. & Dr Chuwanga Clinic & Primary & Buea & N/A \\
\hline 26. & Dr Soliman Clinic & Primary & Buea & N/A \\
\hline 27. & Tiko Central Clinic (TCC) & Primary & Tiko & N/A \\
\hline
\end{tabular}

N/A: Excluded from the study, CMA: Centre Medical d'Arrondissement.

$(2015,2018)$ [9] [10] [11] [12] [13] and the standardized KAP (Knowledge, Attitude and Practice) questionnaire from KAP manual published in 2014 by Food and Agricultural Organization (FAO) [14]. The criteria for scoring obstetric caregivers' knowledge of AMTSL were adapted from a similar study in Ethiopia [10]. The maximum score was 25 , and the knowledge was categorized as good or 
poor ('Table 2).

Data collected was entered in CSPro version 7.3 and analyzed using SPSS version 25. Categorical variables were presented as frequencies and percentages, while continuous variables were expressed as means and standard deviations. Chi-square or Fisher Exact test was used to compare categorical variables where appropriate and Logistic regression was used to identify factors independently associated with knowledge of AMTSL. $P$-values $<0.05$ were considered statistically significant.

\section{Results}

The present study included 150 obstetric caregivers recruited from 27 health facilities in Buea, Limbe and Tiko health districts, of whom, 62 (41.3\%) were nurses, $56(37.3 \%)$ midwives, $26(17.3 \%)$ general medical practitioners and $6(4 \%)$ were obstetricians (Figure 1).

Participants' age ranged from 21 to 67 years with a mean age of $34.19( \pm 9.27)$ years. Most of the participants, $76(50.7 \%)$ were in the age group 21 to 30 years.

Table 2. Criteria for scoring obstetric caregivers' knowledge on AMTSL [10].

\begin{tabular}{ccc}
\hline Caregivers' Knowledge & Scoring (N) & Aggregate score (\%) \\
\hline Poor & $<20$ & $<80$ \\
Good & $20-25$ & $\geq 80$ \\
\hline
\end{tabular}

27 health facilities in Buea, Limbe and Tiko health districts were visited

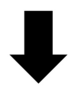

184 obstetric caregivers in total were approached in the various health facilities
34 (18.5\%) obstetric caregivers were excluded from the study due to non-response (One participant due to incomplete filling of the questionnaire)

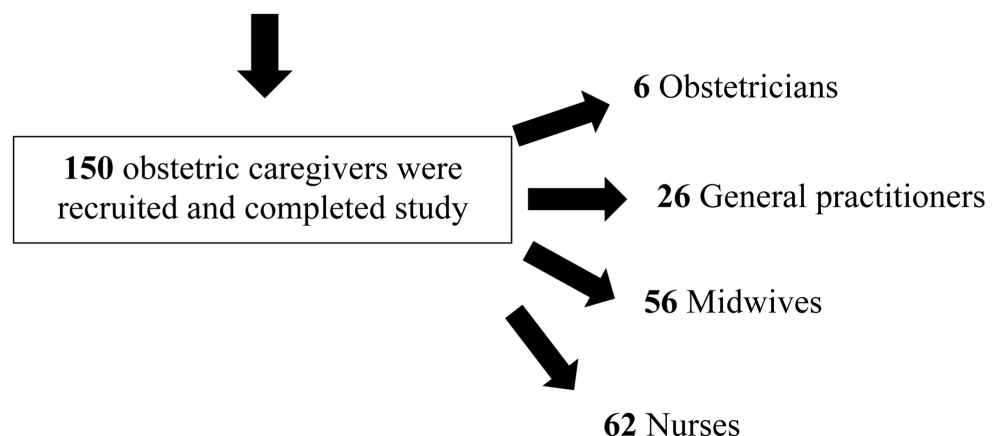

Figure 1. Study consort. 
A great majority of the participants were females, 121 (80.7\%). The mean work experience was $7.77( \pm 7.52)$ years with $50(33.3 \%)$ caregivers having between one to two years of work experience and $43(28.7 \%)$ having more than 10 years of work experience. Furthermore, a majority of the caregivers, 91 (60.7\%) worked in unclassified healthcare facilities (Health centres), 46 (30.7\%) in Primary healthcare facilities (District hospitals) and $13(8.6 \%)$ in a Secondary healthcare facility (Regional Hospital) (Table 3).

Table 3. Socio-demographic characteristics of the study population $(n=150)$.

\begin{tabular}{|c|c|c|}
\hline Variables & Frequency & Percentage (\%) \\
\hline \multicolumn{3}{|l|}{ Age groups } \\
\hline $21-30$ years & 76 & 50.7 \\
\hline $31-40$ years & 40 & 26.7 \\
\hline 41 - 50 years & 25 & 16.7 \\
\hline$>50$ years & 9 & 6.0 \\
\hline Mean $( \pm S D)$ years & $34.19( \pm 9.27)$ & \\
\hline \multicolumn{3}{|l|}{ Sex } \\
\hline Female & 121 & 80.7 \\
\hline Male & 29 & 19.3 \\
\hline \multicolumn{3}{|l|}{ Marital status } \\
\hline Married & 74 & 49.3 \\
\hline Single & 76 & 50.7 \\
\hline \multicolumn{3}{|l|}{ Profession } \\
\hline General medical practitioner & 26 & 17.3 \\
\hline Midwife & 56 & 37.3 \\
\hline Nurse & 62 & 41.3 \\
\hline Obstetrician & 6 & 4.0 \\
\hline \multicolumn{3}{|l|}{ Work experience (years) } \\
\hline $1-2$ years & 50 & 33.3 \\
\hline 3 - 5 years & 32 & 21.3 \\
\hline $6-10$ years & 25 & 16.7 \\
\hline$>10$ years & 43 & 28.7 \\
\hline Mean $( \pm S D)$ years & $7.77( \pm 7.519)$ & \\
\hline \multicolumn{3}{|l|}{ Workplace } \\
\hline Health centre (Unclassified) & 91 & 60.7 \\
\hline District hospital (Primary care centre) & 46 & 30.7 \\
\hline Regional hospital (Secondary care centre) & 13 & 8.6 \\
\hline
\end{tabular}

AMTSL: Active Management of the Third Stage of Labour SD: Standard deviation. 
Also, the majority of caregivers, 146 (97.3\%) knew about AMTSL, 141 (94.0\%) reported using AMTSL, and 126 (84.0\%) had received training on AMTSL, notably with 73 (58.9\%) at the Medical/nursing/midwifery School and 38 (30.6\%) at job training workshops (Table 4).

Globally, only 73 (48.7\%) caregivers had good knowledge of AMTSL (Figure 2 ), of whom $22.7 \%(34 / 150)$ were midwives, $12 \%(18 / 150)$ were general medical practitioners, $12 \%(18 / 150)$ were nurses and 2\% (3/6) were Obstetricians (Figure 3).

Table 4. Training information of participants on AMTSL.

\begin{tabular}{lcc}
\multicolumn{1}{c}{ Variables } & Frequency & Percentage (\%) \\
\hline Do you know AMTSL & 4 & 2.7 \\
No & 146 & 97.3 \\
Yes & & \\
Have you ever received training on AMTSL & 24 & 16.0 \\
No & 126 & 84.0 \\
Yes & & \\
If yes where (n = 124) & 38 & 30.6 \\
At Jobsite training workshop & 7 & 5.6 \\
When observing my colleague performing it & 6 & 4.8 \\
From job aid references & 73 & 58.9 \\
At medical/nursing/midwifery school & & \\
Do you use AMTSL & 9 & 6.0 \\
No & 141 & 94.0 \\
Yes & & \\
\hline
\end{tabular}

AMTSL: Active Management of the Third Stage of Labour.

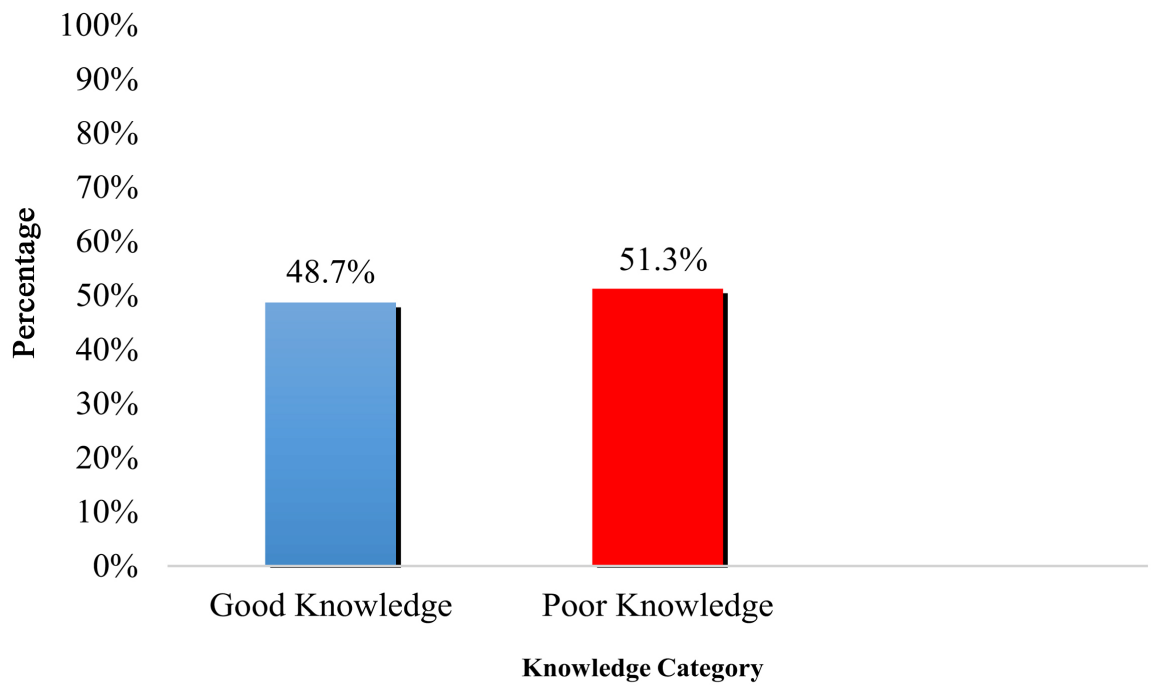

Figure 2. Global or overall knowledge level on AMTSL. 


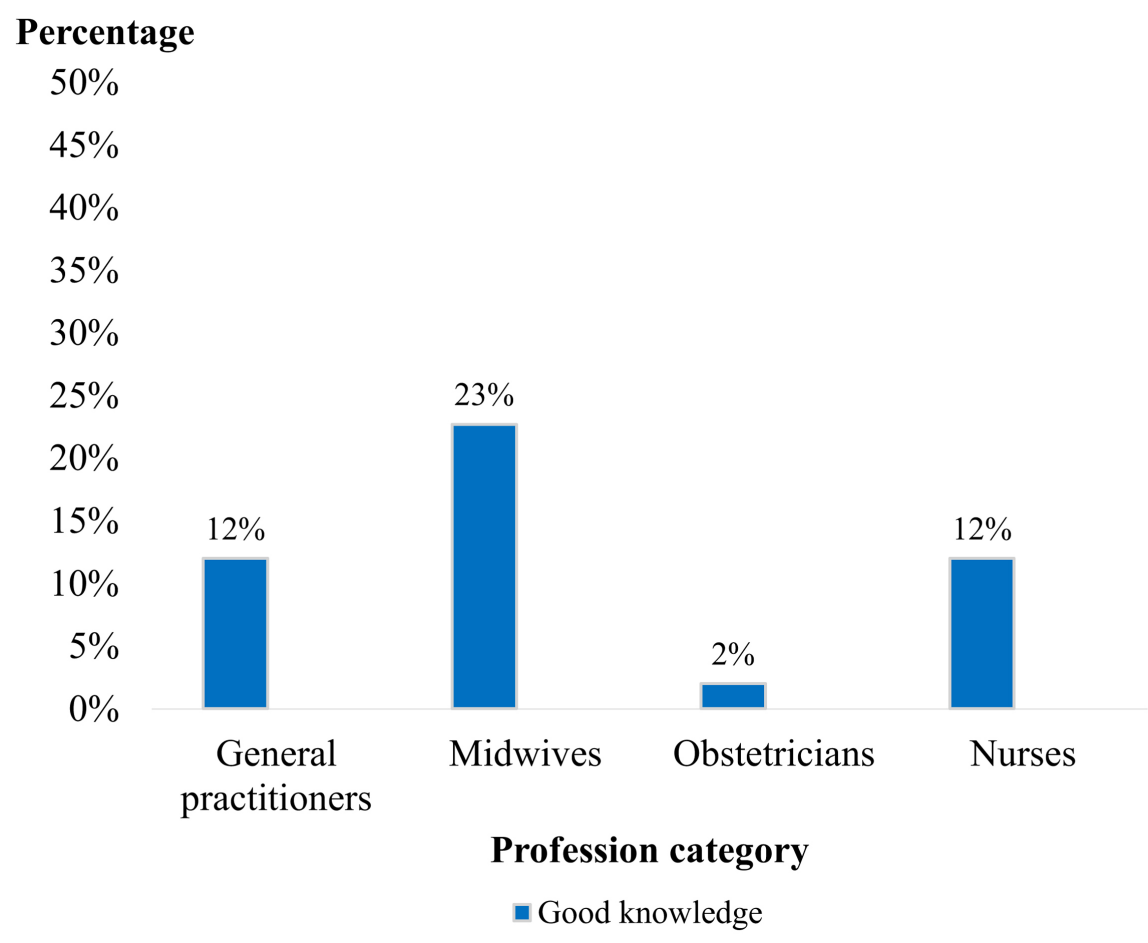

Figure 3. Distribution of good knowledge level on AMTSL per profession.

Only $45.3 \%$ of the caregivers knew all the three components of AMTSL (66.7\% of obstetricians, $55.4 \%$ of midwives, $46.2 \%$ of general medical practitioners and $33.9 \%$ of nurses). However, up to $94.6 \%$ of the caregivers knew of oxytocin as the first line uterotonic drug recommended for AMTSL, 91.1\% knew that the recommended dose of the uterotonic of choice for AMTSL was 10 IU (of oxytocin) and $77.9 \%$ of them reporting IM route as the recommended route to administer the drug during AMTSL.

Only $45.3 \%$ of the caregivers knew all the three components of AMTSL (66.7\% of the obstetricians, $33.9 \%$ of the nurses, $55.4 \%$ of the midwives and $46.2 \%$ of the general medical practitioners).

Besides, $72.4 \%$ of the caregivers knew that AMTSL was to be completed in 5 to 10 minutes and $64.8 \%$ thought that the main goal of AMTSL was to increase the ability of the uterus to contract, facilitate separation of the placenta and to prevent PPH (corresponding to the option "All" on the questionnaire). In addition, $61.6 \%$ of the caregivers disagreed with the administration of $10 \mathrm{IU}$ of oxytocin after delivery of the anterior shoulder. Only $31.4 \%$ of the caregivers agreed with the administration of $10 \mathrm{IU}$ of oxytocin after delivery of the placenta. As much as $87.8 \%$ of the caregivers agreed with the administration of $0.5 \mathrm{mg}$ of ergometrine IM if oxytocin is not available and $64.3 \%$ of caregivers agreed with the administration of $600 \mu \mathrm{g}$ of Misoprostol PO if oxytocin is not available. Clamping and cutting the cord after 1 to 3 minutes following delivery of the baby (Delayed cord clamping) was supported by $79.1 \%$ of the caregivers. About two-thirds of the caregivers (67.9\%) agreed with waiting for a gush of blood before applying CCT and $72.7 \%$ agreed with CCT being done during the contraction. Up to 
$94.5 \%$ of the caregivers agreed with performing UM immediately after delivery and $74.8 \%$ agreed with UM being every 15 mins in the first hour, then every 30 mins in the next hour following delivery of the placenta (Table 5).

Following univariate analysis, good knowledge level on AMTSL was significantly associated with profession $(p<0.001)$, whether they had ever received training on AMTSL $(p=0.037)$ and whether they used AMTSL or not ( $p=$ $0.034)$. No statistically significant association was found between caregivers' years of work experience and a good knowledge of AMTSL.

In multivariate analysis, caregivers who reported using AMTSL were 13 times more likely to have good knowledge of AMTSL compared to those who reported not using it (AOR: 12.96, 95\% CI: $1.12-150.3, p=0.04$ ). The profession and training on AMTSL were confounders (Table 6).

Insufficient staff coverage, $31(22.8 \%)$, unavailability of drugs and/or equipment, 23 (19.9\%) and lack of knowledge and training of the staff, 17 (12.5\%) were the major challenges reported. Furthermore, the challenges varied significantly between caregivers $(p=0.013)$ (Table 7).

Organization of training programs, seminars and workshops on AMTSL following the standard and updated guidelines was the major recommendation proposed by caregivers, 61 (45.9\%). Provision of an adequate supply of oxytocin and other delivery equipment, $21(15.8 \%)$ as well as improvement in staff coverage, 21 (15.8\%) were both greatly recommended too (Table 8).

The use of Standard Operating Procedures (SOPs), charts and/or posters on AMTSL, 76 (69.7\%) pasted on the walls in the maternity ward was the main reference guiding the caregivers' practice of AMTSL. Only six per cent of caregivers reported using WHO or evidence-based practice guidelines to guard their practice of AMTSL. That notwithstanding up to $12(11 \%)$ of respondents did not have any reference guide of their practice of AMTSL (Table 9).

\section{Discussion}

\subsection{Knowledge of Caregivers on AMTSL}

In our study, we observed an overall good knowledge level on AMTSL in 48.7\% of caregivers. This was very high compared to $7.0 \%$ and $10 \%$ of caregivers reported in separate studies in Tanzania and 37.7\% reported in Ethiopia [10] [11] [13]. Our finding was, however, lower than the $51.5 \%$ reported in Ethiopia and $57.8 \%$ and $66.7 \%$ reported in studies carried out in Nigeria [9] [10] [15]. In that line, midwives were the most knowledgeable group with $22.7 \%$ of them with good knowledge of AMTSL. They were followed by general medical practitioners (12\%), nurses (12\%) and lastly obstetricians (2\%). Despite having comparable MMRs to, and better MMRs than some of the countries in the studies aforementioned, this low knowledge level of caregivers on AMTSL is worrisome indicating that AMTSL practice may not be adequate. A possible explanation could be the lack of workshops on AMTSL and/or inadequate pre-service and/or in-service training on AMTSL. Also, the studies carried out in Nigeria, Ethiopia 
Table 5. Knowledge of caregivers on AMTSL (MCQs and Likert scale) $(\mathrm{n}=150)$.

\begin{tabular}{|c|c|c|c|c|c|}
\hline Variable & $\begin{array}{c}\text { General } \\
\text { medical prac- } \\
\text { titioner } \\
\mathrm{n}(\%)\end{array}$ & $\begin{array}{c}\text { Midwife } \\
\text { n (\%) }\end{array}$ & $\begin{array}{l}\text { Nurse } \\
\text { n (\%) }\end{array}$ & $\begin{array}{c}\text { Obstetrician } \\
\text { n (\%) }\end{array}$ & $\begin{array}{l}\text { Total } \\
\text { n (\%) }\end{array}$ \\
\hline \multicolumn{6}{|c|}{ The first line uterotonic recommended for AMTSL is $(n=149)$} \\
\hline Others & $1(4.0)$ & $2(3.6)$ & $5(8.1)$ & $0(0.0)$ & $8(5.4)$ \\
\hline Oxytocin ${ }^{* *}$ & $24(96.0)$ & $54(96.4)$ & 57 (91.9) & $6(100.0)$ & $141(94.6)$ \\
\hline \multicolumn{6}{|c|}{ The recommended dose of that drug during AMTSL is $(n=146)$} \\
\hline Others & $5(19.2)$ & $2(3.6)$ & $5(8.6)$ & $1(16.7)$ & $13(8.9)$ \\
\hline $10 \mathrm{IU}^{* *}$ & $21(80.8)$ & $54(96.4)$ & $53(91.4)$ & $5(83.3)$ & $133(91.1)$ \\
\hline \multicolumn{6}{|c|}{ The recommended route to give that drug during AMTSL is $(n=149)$} \\
\hline Others & $4(15.4)$ & $12(21.4)$ & $15(24.6)$ & $2(33.3)$ & $33(22.1)$ \\
\hline Intramuscular ${ }^{\star *}$ & $22(84.6)$ & $44(78.6)$ & $46(75.4)$ & $4(66.7)$ & $116(77.9)$ \\
\hline \multicolumn{6}{|c|}{ Three main components of AMTSL $(n=150)$} \\
\hline Not aware & $14(53.8)$ & $25(44.6)$ & $41(66.1)$ & $2(33.3)$ & $82(54.7)$ \\
\hline Aware ${ }^{\star *}$ & $12(46.2)$ & $31(55.4)$ & $21(33.9)$ & $4(66.7)$ & $68(45.3)$ \\
\hline \multicolumn{6}{|c|}{ Within how long should AMTSL be completed $(n=134)$} \\
\hline Others $(<5$ mins and $>10$ mins $)$ & $3(13.0)$ & $17(30.8)$ & $15(28.9)$ & $2(50.0)$ & $37(27.6)$ \\
\hline 5 to 10 minutes $^{\star *}$ & $20(87.0)$ & $38(69.1)$ & $37(71.2)$ & $2(50.0)$ & $97(72.4)$ \\
\hline \multicolumn{6}{|c|}{ The main goal of AMTSL is to $(n=145)$} \\
\hline Increase uterine contractility & $0(0.0)$ & $2(3.7)$ & $1(1.6)$ & $0(0.0)$ & $3(2.1)$ \\
\hline Facilitate placental separation & $1(4.2)$ & $3(5.6)$ & $6(9.8)$ & $1(16.7)$ & $11(7.6)$ \\
\hline Prevent PPH & $4(16.7)$ & $14(25.9)$ & $16(26.2)$ & $3(50.0)$ & $37(25.5)$ \\
\hline All ${ }^{* *}$ & $19(79.2)$ & $35(64.8)$ & $38(62.3)$ & $2(33.3)$ & $94(64.8)$ \\
\hline \multicolumn{6}{|c|}{ Administer 10 units of IM oxytocin after delivery of the anterior shoulder ( $n=143$ ) } \\
\hline Disagree & $20(76.9)$ & $27(50.9)$ & $37(63.8)$ & $4(66.7)$ & $88(61.6)$ \\
\hline Agree $^{\star *}$ & $6(23.1)$ & $26(49.1)$ & $21(36.2)$ & $2(33.3)$ & $55(38.5)$ \\
\hline \multicolumn{6}{|c|}{ Administer 10 units of IM oxytocin immediately after delivery of the placenta $(n=140)$} \\
\hline Agree & $9(36.0)$ & $13(24.5)$ & $21(37.5)$ & $1(16.7)$ & $44(31.4)$ \\
\hline Disagree $^{\star *}$ & $16(64.0)$ & $40(75.5)$ & $35(62.5)$ & $5(83.3)$ & $96(68.6)$ \\
\hline \multicolumn{6}{|c|}{ If oxytocin is not available, administer $0.5 \mathrm{mg}$ of Ergometrine IM $(\mathrm{n}=131)$} \\
\hline Agree & $19(82.6)$ & $50(92.6)$ & $42(87.5)$ & $4(66.7)$ & $115(87.8)$ \\
\hline Disagree $^{* *}$ & $4(17.4)$ & $4(7.4)$ & $6(12.5)$ & $2(33.3)$ & $16(12.2)$ \\
\hline \multicolumn{6}{|c|}{ If oxytocin is not available, administer 600 micrograms of Misoprostol (PO) $(n=123)$} \\
\hline Disagree & $12(54.6)$ & $14(28.0)$ & $15(32.6)$ & $3(60.0)$ & $44(35.8)$ \\
\hline Agree ${ }^{\star \star}$ & $10(45.4)$ & $36(72.0)$ & $31(67.4)$ & $2(40.0)$ & $79(64.2)$ \\
\hline \multicolumn{6}{|c|}{ Clamp and cut the cord after 1-3 minutes following delivery of the baby ( $n=139$ ) } \\
\hline Disagree & $7(28.0)$ & $9(16.4)$ & $12(22.2)$ & $1(20.0)$ & $29(20.9)$ \\
\hline
\end{tabular}


Continued

Agree**

$18(72.0)$

$46(83.6)$

$42(77.8)$

$4(80.0)$

$104(79.1)$

Wait for a strong uterine contraction (2-3 minutes) before delivering the placenta $(n=143)$

Disagree

$$
2(7.7)
$$

$17(32.0)$

$9(15.5)$

$1(16.7)$

$29(20.2)$

Agree $^{* *}$

$24(92.3)$

$36(68.0)$

$49(84.5)$

$5(83.3)$

$114(79.8)$

Wait for a gush of blood before applying controlled cord traction CCT $(n=140)$

Disagree ${ }^{* *}$

6 (25.0)

14 (26.0)

22 (39.3)

3 (50.0)

45 (32.3)

Agree

18 (75.0)

40 (74.0)

34 (60.7)

3 (50.0)

95 (67.9)

Controlled cord traction (CCT) is done during the contraction $(n=139)$

Disagree

$6(24.0)$

$16(19.7)$

$16(29.6)$

$0(0.0)$

$38(27.3)$

Agree $^{* *}$

$19(76.0)$

$38(70.3) \quad 38(70.4)$

$6(100.0)$

$101(72.7)$

Uterine massage is done immediately after delivery of the placenta $(n=145)$

$\begin{array}{lccccc}\text { Disagree } & 2(8.0) & 1(1.8) & 5(8.5) & 0(0.0) & 8(5.5) \\ \text { Agree }^{* *} & 23(92.0) & 54(98.2) & 54(91.5) & 6(100.0) & 137(94.5)\end{array}$

Uterine massage is done every 15 mins in the first hour, then every 30 mins in the next hour following delivery of the placenta $(n=139)$

$\begin{array}{lccccc}\text { Disagree } & 6(26.0) & 18(33.3) & 10(17.2) & 1(25.0) & 35(25.2) \\ \text { Agree }^{* *} & 15(74.0) & 36(66.7) & 48(82.8) & 3(75.0) & 104(74.8)\end{array}$

**: Correct response; AMTSL: Active Management of the Third Stage of Labour; PPH: Postpartum Haemorrhage.

Table 6. Determinants of good knowledge of AMTSL $(n=150)$.

\begin{tabular}{|c|c|c|c|c|c|c|}
\hline \multirow[t]{2}{*}{ Variables } & \multicolumn{3}{|c|}{ Knowledge on AMTSL n (\%) } & \multirow{2}{*}{$\begin{array}{c}\text { Univariate } \\
\text { analysis } \\
p \text {-value }\end{array}$} & \multicolumn{2}{|c|}{ Multivariate analysis } \\
\hline & Poor & Good & Total & & AOR $(95 \% \mathrm{CI})$ & $p$-value \\
\hline \multicolumn{7}{|c|}{ Profession $(n=150)$} \\
\hline $\begin{array}{l}\text { General medical } \\
\text { practitioner }\end{array}$ & $8(10.4)$ & $18(24.7)$ & $26(17.3)$ & \multirow{4}{*}{$<0.001$} & $0.28(0.04-1.85)$ & 0.187 \\
\hline Midwife & $22(28.6)$ & $34(46.6)$ & $56(37.3)$ & & $0.65(0.12-3.50)$ & 0.611 \\
\hline Nurse & $44(57.1)$ & $18(24.7)$ & $62(41.3)$ & & $2.17(0.39-12.03)$ & 0.374 \\
\hline Obstetrician & $3(3.9)$ & $3(4.1)$ & $6(4.1)$ & & 1 & \\
\hline \multicolumn{7}{|c|}{ Have you ever received training on AMTSL $(n=150)$} \\
\hline Yes & $60(77.9)$ & $66(90.4)$ & $126(84.0)$ & \multirow{2}{*}{0.037} & $1.05(0.34-3.26)$ & 0.932 \\
\hline No & $17(22.1)$ & $7(9.6)$ & $24(16.0)$ & & 1 & \\
\hline \multicolumn{7}{|c|}{ Do you use AMTSL $(n=150)$} \\
\hline Yes & $69(89.6)$ & $72(98.6)$ & $141(94.0)$ & \multirow[b]{2}{*}{0.034} & $12.96(1.12-150.30)$ & 0.040 \\
\hline No & $8(10.4)$ & $1(1.4)$ & $9(6.0)$ & & 1 & \\
\hline
\end{tabular}

AMTSL: Active Management of the Third Stage of Labour, AOR: Adjusted Odds ratio; CI: Confidence interval. 
Table 7. Challenges of caregivers to AMTSL practice $(n=136)$.

\begin{tabular}{|c|c|c|c|c|c|c|}
\hline Variables & $\begin{array}{c}\text { General } \\
\text { medical } \\
\text { practitioner } \\
\text { n (\%) }\end{array}$ & $\begin{array}{l}\text { Midwife } \\
\text { n (\%) }\end{array}$ & $\begin{array}{l}\text { Nurse } \\
\text { n (\%) }\end{array}$ & $\begin{array}{l}\text { Obstetrician } \\
\text { n (\%) }\end{array}$ & $\begin{array}{l}\text { Total } \\
\text { n (\%) }\end{array}$ & $p$-value \\
\hline \multicolumn{7}{|c|}{ Challenges on the implementation of AMTSL $(n=136)$} \\
\hline $\begin{array}{l}\text { Unavailability of } \\
\text { drugs/equipment }\end{array}$ & $5(21.7)$ & $11(20.8)$ & $5(9.3)$ & $2(33.3)$ & $23(16.9)$ & 0.013 \\
\hline $\begin{array}{l}\text { Mother's refusal to } \\
\text { cooperate }\end{array}$ & $0(0.0)$ & $5(9.4)$ & $6(11.1)$ & $0(0.0)$ & $11(8.1)$ & \\
\hline Placenta accreta/retention & $0(0.0)$ & $9(17.0)$ & $8(14.8)$ & $0(0.0)$ & $17(12.5)$ & \\
\hline Insufficient staff coverage & $7(30.4)$ & $9(17.0)$ & $15(27.8)$ & $0(0.0)$ & $31(22.8)$ & \\
\hline $\begin{array}{l}\text { Complications such as } \\
\text { bleeding }\end{array}$ & $1(4.3)$ & $1(1.9)$ & $5(9.3)$ & $0(0.0)$ & $7(5.1)$ & \\
\hline $\begin{array}{l}\text { Lack of knowledge and } \\
\text { training of staff }\end{array}$ & $6(26.2)$ & $2(3.8)$ & $6(11.1)$ & $3(50.0)$ & $17(12.5)$ & \\
\hline No challenge & $4(17.4)$ & $16(30.2)$ & $9(16.7)$ & $1(16.7)$ & $30(22.1)$ & \\
\hline
\end{tabular}

Bold, statistically significant, AMTSL, Active Management of the Third Stage of Labour. $p$-values from Chi-square and fisher exact test.

Table 8. Recommendations to improve AMTSL practice $(\mathrm{n}=133)$.

\begin{tabular}{|c|c|c|c|c|c|}
\hline Variable & $\begin{array}{l}\text { General medical } \\
\text { practitioner } \\
\text { n (\%) }\end{array}$ & $\begin{array}{l}\text { Midwife } \\
\text { n (\%) }\end{array}$ & $\begin{array}{l}\text { Nurse } \\
\text { n (\%) }\end{array}$ & $\begin{array}{l}\text { Obstetrician } \\
\mathrm{n}(\%)\end{array}$ & $\begin{array}{l}\text { Total } \\
\text { n (\%) }\end{array}$ \\
\hline \multicolumn{6}{|c|}{ Suggestions for reinforcement of AMTSL $(n=133)$} \\
\hline $\begin{array}{l}\text { Perform abdominal massage and } \\
\text { controlled cord traction }\end{array}$ & $1(4.0)$ & $1(2.0)$ & $1(1.9)$ & $0(0.0)$ & $3(2.3)$ \\
\hline $\begin{array}{l}\text { Proper health education and } \\
\text { adequate assessment of women } \\
\text { before delivery }\end{array}$ & $0(0.0)$ & $4(8.2)$ & $5(9.4)$ & $0(0.0)$ & $9(6.8)$ \\
\hline $\begin{array}{l}\text { Trainings//Workshops and } \\
\text { seminars/Update of information }\end{array}$ & $17(68.0)$ & $22(44.9)$ & $17(32.1)$ & $5(83.3)$ & $61(45.9)$ \\
\hline $\begin{array}{l}\text { Adequate supply of oxytocin and } \\
\text { other delivery equipment }\end{array}$ & $4(16.0)$ & $8(16.3)$ & $9(17.0)$ & $0(0.0)$ & $21(15.8)$ \\
\hline Improve staff coverage & $2(8.0)$ & $6(12.3)$ & $13(24.5)$ & $0(0.0)$ & $21(15.8)$ \\
\hline None & $1(4.0)$ & $8(16.3)$ & $8(15.1)$ & $1(16.7)$ & $18(13.4)$ \\
\hline
\end{tabular}

AMTSL, Active Management of the Third Stage of Labour.

and Tanzania [9] [10] [11] [13] [15] principally assessed midwives and nurses, meanwhile our study assessed physicians, midwives and nurses. Besides, physicians in the studied health facilities are usually called up to manage complicated third stages of labour and hence take less part in uncomplicated deliveries [16]. 
Table 9. Reference guide of AMTSL practice $(n=109)$.

\begin{tabular}{|c|c|c|c|c|c|}
\hline Variable & $\begin{array}{l}\text { General medi- } \\
\text { cal practitioner } \\
\text { n (\%) }\end{array}$ & $\begin{array}{l}\text { Midwife } \\
\text { n (\%) }\end{array}$ & $\begin{array}{l}\text { Nurse } \\
\text { n (\%) }\end{array}$ & $\begin{array}{l}\text { Obstetrician } \\
\text { n (\%) }\end{array}$ & $\begin{array}{l}\text { Total } \\
\text { n (\%) }\end{array}$ \\
\hline \multicolumn{6}{|c|}{ Reference at workplace on how to perform AMTSL $(n=109)$} \\
\hline Use of partograph & $1(4.3)$ & $7(16.3)$ & $2(5.3)$ & $0(0.0)$ & $10(9.2)$ \\
\hline $\begin{array}{l}\text { Presence of charts, SOPs and } \\
\text { posters in the maternity }\end{array}$ & $18(78.4)$ & $28(65.1)$ & $25(65.7)$ & $5(100.0)$ & $76(69.7)$ \\
\hline WHO/Evidence based practice & $3(13.0)$ & $1(2.3)$ & $2(5.3)$ & $0(0.0)$ & $6(5.5)$ \\
\hline From experienced staff & $0(0.0)$ & $0(0.0)$ & $2(5.3)$ & $0(0.0)$ & $2(1.8)$ \\
\hline $\begin{array}{l}\text { Capacity building programs and } \\
\text { hospital meetings }\end{array}$ & $0(0.0)$ & $3(7.0)$ & $0(0.0)$ & $0(0.0)$ & $3(2.8)$ \\
\hline None & $1(4.3)$ & $4(9.3)$ & $7(18.4)$ & $0(0.0)$ & $12(11.0)$ \\
\hline
\end{tabular}

AMTSL, Active Management of the Third Stage of Labour, SOPs, Standard Operating Procedures.

When assessing the caregivers' knowledge of the components of AMTSL, we observed that less than half of the caregivers (45.3\%) knew all the three main components of AMTSL. Our finding was higher than that reported in South Africa (36.0\%) [17] but was however very low compared to findings in Tanzania (70.1\%), Ethiopia (63.2\% and 58.0\%) and Lesotho (62.2\%) [10] [11] [16] [18]. The majority of respondents were able to state at most 2 of the components correctly. A possible explanation could lie in the difference in the questionnaire used in our respective studies. Ours had open-ended questions while theirs had multiple choice questions for one to select the right answer. This reduced the chance of guess work.

The Guideline Development Group (GDG) of WHO considered the use of uterotonics as the main intervention within AMTSL, and, in our study, administration of uterotonics was the most frequently reported AMTSL component by the caregivers. This shows that despite not knowing all the components of AMTSL, many knew the most important component.

\subsection{Determinants of Knowledge of Caregivers on AMTSL}

The fact that caregivers' use of AMTSL was the only factor independently associated with good knowledge of AMTSL in our study contrasted with a similar study carried out in Ethiopia [16] where the profession of the caregivers was the only independently associated factor to a good knowledge of AMTSL. Caregivers who reported using AMTSL were more likely to have good knowledge on it as compared to those who reported not using it. This can be explained by the saying practice makes perfect, as their regular use of AMTSL has urged them to know all about it to ensure adequate practice and thus has improved their knowledge on the subject. 


\subsection{Challenges to AMTSL Utilization}

Insufficient staff coverage (22.8\%) was the major challenge to the use of AMTSL faced by caregivers. This challenge was also reported by caregivers interviewed in similar studies carried out in Ghana and Tanzania [8] [11]. Unavailability of drugs and equipment, as well as lack of knowledge and training on AMTSL, were also major challenges reported in Tanzania, Ghana and Nigeria [8] [11] [15].

The recommendations for better practice of AMTSL proposed by the caregivers under study were in line with the challenges they reported; with the organization of training programs, seminars and workshops on AMTSL following the standard and updated guidelines, provision of an adequate supply of oxytocin and other delivery equipment as well as improvement of staff coverage being the major recommendations they proposed.

Our study also revealed that $11 \%$ of caregivers did not have any reference guiding their practice of AMTSL. Moreover, only six per cent of the caregivers reported using guidelines from international bodies like WHO or evidencebased practice to guide their practice of AMTSL. The Majority of them used standard operating procedures (SOPs), charts and/or posters on AMTSL (69.7\%) pasted on the walls in the maternity ward as the main reference guiding their practice of AMTSL confirming the hypotheses that most caregivers rely more on standard operating procedures (SOPs) (usually pasted on the walls of maternity units) rather than actual (updated) guidelines or directives on AMTSL [19]. Therefore, there was no scientific backing of their practice [20].

\subsection{Strengths and Limitations}

A qualitative arm of this study could enlighten us more on the challenges faced by caregivers on the practice of AMTSL.

Our study included physicians (obstetricians and general medical practitioners), which only a few studies in sub-Saharan Africa have done.

Finally, our study was the first to assess obstetric caregivers' knowledge on AMTSL, the challenges they face in its use and the determinants of good knowledge on AMTSL in Cameroon.

\section{Conclusions}

There is a knowledge gap in AMTSL among obstetric caregivers in Buea, Limbe and Tiko health districts with less than half having good knowledge.

Caregivers' use of AMTSL was the only determinant of good knowledge of AMTSL identified in these health districts.

Challenges reported by the caregivers in the practice of AMTSL included the lack of training and workshops, insufficient staff coverage and the unavailability of drugs and/or equipment.

These challenges could account for the high MMR from PPH in Cameroon despite AMTSL use as well as the slow progress towards achieving SDG3. 


\section{Ethical Approval and Consent to Participate}

Approvals for this study were obtained from the Institutional Review Board (IRB) of the Faculty of Health Sciences of the University of Buea (FHS-UB), [Ref. No. 2020/1057-01/UB/SG/IRB/FHS]; the Regional Delegation of Public Health for the South West Region [Ref. No. R11/MINSANTE/SWR/RDPH/PS/496/786], the District Medical Officers (DMOs) of Buea [Ref. No. FVol2/L/MINSANTE/ RDPH SW/DHS Buea/159], Limbe [Ref. No. 413B/SWR/RDPH/DMOL/33] and Tiko Health Districts, [Ref. No. 2020/28II/MINSANTE/RDPHSW/THD-65] and the Directors of the selected health facilities.

All eligible participants were informed on the aim and objectives of the study and possible adverse effects (time-consuming to fill questionnaires) after which the information sheet was given to each of them. Participants were given opportunities to ask questions for clarity. Participants who accepted to be part of the study gave written consent. No material or financial incentives were given to encourage participation in the study. Confidentiality was ensured by coding and keeping the data collected very securely through the use of passwords only accessible to the principal investigator. No information on identification such as names was obtained from the participants, rather codes were used to make sure it could not be traced back to them.

\section{Availability of Data and Materials}

The authors declare that data sufficient to produce the presented results will be made available on reasonable request to the Department of Obstetrics and Gynaecology, Faculty of Health Sciences, University of Buea. Data requests can be submitted through the corresponding author.

\section{Authors' Contributions}

Tih William Ntchompbopughu: Conception of the topic, designed the protocol, carried out data collection, drafted the manuscript.

Egbe Obinchemti Thomas: Conception of the topic, Supervised, interpreted the results, revised and edited the manuscript.

Tendongfor Nicholas: Data analysis, review and editing of the manuscript.

\section{Acknowledgements}

We sincerely wish to acknowlege the directors of the various health facility where data was collected and the health caregivers who participated in this study.

\section{Conflicts of Interest}

The authors declare having no conflict of interest.

\section{References}

[1] Shadap, A. (2019) Knowledge and Practice of Active Management of the Third Stage of Labour (AMTSL) among Nursing Students in Selected Hospitals, Gangtok, 
Sikkim. International Journal of Nursing and Midwifery Research, 5, 59-66. https://doi.org/10.24321/2455.9318.201849

[2] CIA World Factbook (2019) Maternal Mortality Rate, Country Comparisons, Ranks, by Rank. https://photius.com/rankings/2019/population/maternal mortality rate 20190. ht $\underline{\mathrm{ml}}$

[3] Ministry of Public Health, National Institute of Statistics (2020) Demographic Health Survey 2018. Cameroon. 21-25.

[4] Halle-Ekane, et al. (2016) Prevalence and Risk Factors of Primary Postpartum Hemorrhage after Vaginal Deliveries in the Bonassama District Hospital, Cameroon. International Journal of Tropical Disease and Health, 13, 1-12. https://doi.org/10.9734/IJTDH/2016/23078

[5] Tebeu, P.-M., Halle-Ekane, G., Itambi, M.D., Mbu, R.E., Mawamba, Y. and Fomulu, J.N. (2015) Maternal Mortality in Cameroon: A University Teaching Hospital Report. Pan African Medical Journal, 21, Article No. 16.

[6] Bestman, P.L., Pan, X. and Luo, J. (2019) The Prevalence and Risk Factors of PostPartum Haemorrhage in Africa: A Systematic Review. PMC Europe. (preprint) https://doi.org/10.21203/rs.2.19608/v1

[7] World Health Organization, UNICEF, United Nations, Department of Economic and Social Affairs, Population Division, World Bank (2015) Trends in Maternal Mortality: 1990 to 2015. Estimates by WHO, UNICEF, UNFPA, World Bank Group and the United Nations Population Division, 16-18.

[8] Schack, S., Elyas, A., Brew, G. and Odberg Pettersson, K. (2014) Experiencing Challenges When Implementing Active Management of the Third Stage of Labor (AMTSL): A Qualitative Study with Midwives in Accra, Ghana. BMC Pregnancy and Childbirth, 14, Article No. 193. https://doi.org/10.1186/1471-2393-14-193

[9] Oyetunde, M.O. and Nkwonta, C.A. (2015) Assessment of Midwives' Competence in Active Management of the Third Stage of Labour in Primary Health Centres in Anambra State, Nigeria. Journal of Applied Medical Sciences, 4, 17-29.

[10] Henok, A. and Yaekob, R. (2015) Factors Associated with Knowledge, Attitude and Practice of Midwives on Active Management of the Third Stage of Labour at Selected Health Centers of Addis Ababa, Ethiopia. Journal of Resources, Development and Management, 10, 54-61.

[11] Ramadhani, F.B. (2011) Midwives' Competency for Implementation of Active Management of the Third Stage of Labor in Dar es salaam Municipal Hospitals, Tanzania. 85 .

[12] Alemu, A. (2019) Active Management of the Third Stage of Labour: Practice and Associated Factors among Obstetric Care Providers' at Health Facilities in Kambata-Tembaro Zone, Southern Ethiopia 2018. International Journal of Pregnancy and Child Birth, 5, 92-97. https://doi.org/10.15406/ipcb.2019.05.00154

[13] Mfinanga, G.S., Kimaro, G.D., Ngadaya, E., Massawe, S., Mtandu, R., Shayo, E.H., et al. (2009) Health Facility-Based Active Management of the Third Stage of Labour: Findings from a National Survey in Tanzania. Health Research Policy and Systems, 7, Article No. 6. https://doi.org/10.1186/1478-4505-7-6

[14] Fautsch Macías, Y. and Glasauer, P. (2014) Food and Agriculture Organization of the United Nations. Guidelines for Assessing Nutrition-Related Knowledge, Attitudes and Practices. Food and Agriculture Organization of the United Nations, Rome. http://books.google.com/books?id=SJB40wU72scC

[15] Asibong, U., Akpan, U. and Ayi, E. (2018) Active Management of the Third Stage of 
Labour: Knowledge and Practice among Non-Physician Obstetric Care-Givers in Primary Health Care Setting in Calabar Municipality, South-South Nigeria. Research in Obstetrics and Gynaecology, 6, 9-15.

[16] Tenaw, Z., Yohannes, Z. and Amano, A. (2017) Obstetric Care Providers' Knowledge, Practice and Associated Factors towards Active Management of the Third Stage of Labour in Sidama Zone, South Ethiopia. BMC Pregnancy and Childbirth, 17, Article No. 292. https://doi.org/10.1186/s12884-017-1480-8

[17] Daef, G., Naidoo, T.D. and Moodley, J. (2017) An Audit of the Knowledge and Practice of the Active Management of the Third Stage of Labour in a Resource-Constrained Setting. Journal of Community and Public Health Nursing, 3, Article No. 20061.

[18] Muzeya, F. (2015) Knowledge, Attitudes and Practices of Nurse-Midwives Related to Obstetric Care at Thaba-Tseka District in Lesotho. 143.

[19] Mugambi, B.K. (2018) Knowledge and Competency of Midwives in Implementation of Active Management of the Third Stage of Labour in Meru County, Kenya. 101.

[20] Efstathiou, G., Papastavrou, E., Raftopoulos, V. and Merkouris, A. (2011) Factors Influencing Nurses' Compliance with Standard Precautions to Avoid Occupational Exposure to Microorganisms: A Focus Group Study. BMC Nursing, 10, Article No. 1. https://doi.org/10.1186/1472-6955-10-1 


\section{Appendix: Data Collection Form (English Version)}

Active Management of the Third Stage of Labour (AMTSL)

Competency Assessment Questionnaire

TITLE: Active Management of the Third Stage of Labour (AMTSL): Knowledge and Challenges of Obstetric caregivers in selected health facilities in Fako division, Cameroon.

Participants: Obstetricians, General practitioners, Midwives and Nurses in the maternity ward.

Section One: Socio-demographic data.

Instructions: Please fill the blank spaces and encircle/tick the single most correct answer in each multiple-choice question.

Participant Code (For Investigator use only)

1) Age.

2) Sex........F/M

3) Marital status
(a) Single
(b) Married
(c) Divorced
4) Profession
(a) Obstetrician
(b) General medical practitioner
(c) Midwife
(d) Nurse
5) For how long have you been practising?
6) Where do you work? (Years of experience)
(a) Health centre
(b) District Hospital
(c) Regional Hospital
(d) Reference Hospital

Training information on AMTSL.

7) Do you know AMTSL?
(a) Yes
(b) No

If yes continue to question (8) below, if no please give reasons

8) Have you ever received any training on AMTSL?
(a) Yes
(b) No

If no, continue to question (9) below, if Yes then where?
(a) At medicine/midwifery/nursing school
(b) At job training workshop
(c) When observing my colleagues performing it on a woman
(d) From job aid references
(e) Other (Please specify) 
9) Do you use AMTSL?
(a) Yes
(b) No.

If no, please give reasons.

\section{Section Two: Knowledge of AMTSL}

Instructions: Please circle the single most correct answer in each multiple-choice question.

1) Postpartum haemorrhage ( $\mathrm{PPH})$ is blood loss of about
(a) $1000 \mathrm{ml}$
(b) $800 \mathrm{ml}$
(c) $500 \mathrm{ml}$
(d) $400 \mathrm{ml}$
(e) $1000 \mathrm{ml}$ and $500 \mathrm{ml}$
2) How do you routinely measure postpartum blood loss?
(a) Estimated blood loss
(b) Blood indices (Haemoglobin, Haematocrit)
(c) Other (please specify)
(d) Estimate blood loss and Blood indices
3) How do you recognize PPH?
(a) Estimated blood loss
(b) Symptoms and signs of cardiovascular compromise
(c) All
(d) Others (Please specify).
4) Causes of immediate postpartum haemorrhage
(a) Uterine atony
(b) Retained placenta and/or membranes
(c) Traumatic delivery
(d) Bleeding disorders
(f) All
(g) Others (Please specify).

5) The first line uterotonic recommended for AMTSL is
(a) Ergometrine
(b) Oxytocin
(c) Misoprostol
(d) Other (Please specify)
6) The recommended dose of that drug (selected in Question 5 above) during AMTSL is
(a) 5 IU
(b) $10 \mathrm{IU}$
(c) 2.5. IU
(d) Other (Please specify)
7) The recommended route to give that drug (selected in Question 5 above) during AMTSL is

(a) Oral 
(b) Intramuscular (IM)

(c) Intravenous (IV)

(d) Other (Please specify)

8) What are the three main components of AMTSL?

a).

b).

c).

9) Within how long should AMTSL be completed?
(a) 1 minute, if relaxed within 3 minutes
(b) 5 minutes
(c) 5 - 10 minutes
(d) Other (Please specify)...
10) The main goal of AMSTL is to:
(a) Increase the ability of the uterus to contract
(b) Facilitate separation of the placenta
(c) Prevent $\mathrm{PPH}$
(d) All
(e) Other (Please specify)

\section{Section Three: Practice of AMTSL}

Instructions: place a tick in the box corresponding to the option of your choice.

$\begin{array}{cccccc}\text { Procedure: } & \text { Strongly } & \text { Agree } & \text { Strongly } & & \text { No De- } \\ \text { Disagrees } & \begin{array}{c}\text { No } \\ \text { Activion }\end{array} \\ \text { Third Stage of Delivery } & \text { Agree } & \text { (A) } & \text { (S/D) } & \text { (D) } & \text { (N/D) }\end{array}$

After delivering the first baby,

1. palpate the abdomen and rule out the presence of another fetus before continuing? Administer 10 units of IM

2. oxytocin after delivery of the anterior shoulder

Administer 10 units of IM

3. oxytocin immediately after delivery of the placenta If oxytocin is not available,

4. administer $0.5 \mathrm{mg}$ of Ergometrine IM

If oxytocin is not available,

5. administer $600 \mu \mathrm{g}$ of Misoprostol per os (PO)

Clamp and cut the cord after

6. 1 - 3 minutes following delivery of the baby 


\section{Continued}

Clamp and cut the cord in

7. less than 1 minute if the baby is asphyxiated

Wait for a strong uterine

8. contraction ( 2 - 3 minutes) before delivering the placenta

Wait for a gush of blood

9. before applying controlled cord traction (CCT)

Controlled cord traction (CCT) is done during the contraction

The placenta is supported

11. with both hands following its delivery

Extraction of the placental

12. membranes is done gently with lateral (clockwise) movements

Uterine massage is done

13. immediately after delivery of the placenta

Examine the placenta for

14. completeness following its delivery

Uterine massage is done every 15 mins in the first hour, then

15. every 30 mins in the next hour following delivery of the placenta

\section{Section Four: Challenges faced in the implementation of AMTSL.}

Instructions: Fill the spaces provided below

1) What challenges do you face in the implementation of AMTSL in your setting?

2) What would you like to suggest to improve AMTSL implementation?

3) List at least one reference at your workplace that guides how to perform AMTSL 